ECCOMAS

\section{Proceedia}

COMPDYN 2021

$8^{\text {th }}$ ECCOMAS Thematic Conference on Computational Methods in Structural Dynamics and Earthquake Engineering

M. Papadrakakis, M. Fragiadakis (eds.) Streamed from Athens, Greece, 28 - 30 June 2021

\title{
GAUSSIAN AND NON-GAUSSIAN WIND TUNNEL PROCESSES
}

\author{
Di Giovanni M. ${ }^{1^{*}}$, D’Asdia P. ${ }^{2}$ \\ ${ }^{1}$ University G. D’Annunzio, School of Engineering, viale Pindaro 42, 65127, Pescara, \\ e-mail:dgm.studio@outlook.it, corresponding author \\ ${ }^{2}$ University G. D’Annunzio, School of Engineering, viale Pindaro 42, 65127, Pescara, \\ e-mail:pierodasdia@gmail.com
}

\begin{abstract}
The wind-structure interaction for structures sensitive to the wind action is commonly investigated through experimental campaigns in wind tunnel. Aerodynamic tests on rigid body models are carried out to estimate pressure coefficients that in turn are used to estimate the wind action on the prototype surfaces. Pressure taps are located on the model surfaces and pressure scanners acquire pressure time histories. Pressure coefficients are calculated from pressure series, they are dimensionless values and they are nondimensionalized on the wind velocity. In the wind tunnel, the flow is assumed stationary and consequently the mean value of pressure coefficient time history is independent of the experiment time length. However, the acquisition time length affects peak values and in particular the peak factor. In addition, the most of processes acquired near edges and near the flow detachment zones are non-Gaussian, contrary to what codes and standard suggest. It was estimated that several processes on the surfaces of a rigid body are non-Gaussian and, in this case, the mean value is not significant. At contrary, the mean value is mostly assumed as representative value of a measurement and it is used to size the structure. It is true only for some specific zones. In addition, they depend on the wind angle of attack. The purpose of this study is to discusses the Gaussian and nonGaussian processes localization for two examples of structure families, large span roofs and bridge closed box section using aerodynamic experiments given by literature. The geometries subject of this investigation are typical geometries of roofs and bridge sections sensitive to wind action as for example cable nets roofs and suspended bridges.
\end{abstract}

Keywords: Wind tunnel, light structure, random processes, Gaussianity, stochastics. 


\section{INTRODUCTION}

The wind tunnel experimental campaign is largely used to estimate the wind effects on structures sensitive to the wind. Structures very sensitive to the wind action are generally large span roofs [1-5] as for example tensile structures for which the permanent load is smaller than the wind action, suspended bridges [6] that differently than traditional bridges made of reinforced concrete that are sensitive to the seismic action [7] or steel corrosion [8] can be affected by the flutter instability and finally, high-rise buildings [9] that are slender.

The wind tunnel is used to investigate the aerodynamics and the aeroelastic behavior of structures. The aerodynamics is commonly investigated through rigid body models and the test purpose is to estimate pressures using tubes and pressure taps [1] or wind forces using beam balances. The aeroelastic behavior is investigated through dynamic models that reproduces the prototype masses and stiffness based on scaling laws [10-14].

Aerodynamic and aeroelastic wind tunnel tests are both carried out for structures very light and for which instability due to wind effects is expected. However, it is well known that the more common experiments in wind tunnel are intended to estimate the wind action on the structure surface through the pressure distribution. The pressure distributions across the test model have historically been measured by drilling small holes (i.e. pressure taps) along the airflow path and using multi-tube manometers to measure the pressure at each hole. Pressure distributions can more conveniently be measured using pressure-sensitive paint, in which higher local pressure is indicated by lowered fluorescence of the paint at that point. Pressure distributions can also be conveniently measured using pressure-sensitive pressure belts, a recent development in which multiple ultra-miniaturized pressure sensor modules are integrated into a flexible strip. The strip is attached to the aerodynamic surface with tape, and it sends signals depicting the pressure distribution along its surface, [15].

The main results obtained from pressure tests is the pressure coefficients that depend on the building shape and the turbulence flow. The experimental data are time histories and stationary processes. Many codes [16-17] suggest assuming the mean value of the pressure coefficient time history as a representative value for the wind action estimation. It is because codes assuming that the random processes acquired in wind tunnel are gaussian [18] and consequently, the distribution of values is centered around the mean value. However, several studies have shown that in many cases, processes acquired in wind tunnel are not Gaussian, [19-23] and the skewness and kurtosis of the process are not negligible [24]. For these cases the mean value can be not representative of the phenomenon. Another important statistic parameter of a random process is the absolute maximum that depends on the peak factor that in turn depends on the time length of the process. The peak factor can be predicted analytically through models that assume that the process is Gaussian [18] or not-Gaussian [25-31]. This is a hot topic in the scientific literature because codes suggest the common value of the peak factor of 3.5 that is commonly smaller than the experimental value.

This paper discusses the statistics of random processes acquired in wind tunnel during different experimental campaign on roofs and bridge sections. The pressure coefficients time histories peak factors are plotted comparing to the $95 \%$ level of confidence given by [18] and the number of Gaussian and non-Gaussian processes were compared.

\section{RANDOM PROCESSES STATISTICS}

In this paper two set of pressure coefficients time histories are discussed. The first one consists of pressure coefficients time histories acquired on hyperbolic paraboloid roofs given by [21] (Fig.1) and the second one consists of pressure coefficients time histories acquired on closed box section of suspended bridges (Fig.2). 
The experimental campaign of hyperbolic paraboloid roofs discussed by [21] consists of sixteen different geometries of hyperbolic paraboloid roofs with different plan shape (i.e. square, rectangular, circular, and elliptical), two different curvature (i.e. more curved and flatter) and two different heights (i.e. tall and low). All geometries were tested in wind tunnel to acquire pressure coefficients subsequently published in [16]. Models were equipped with pressure taps (Fig.1) connected to pressure scanners.

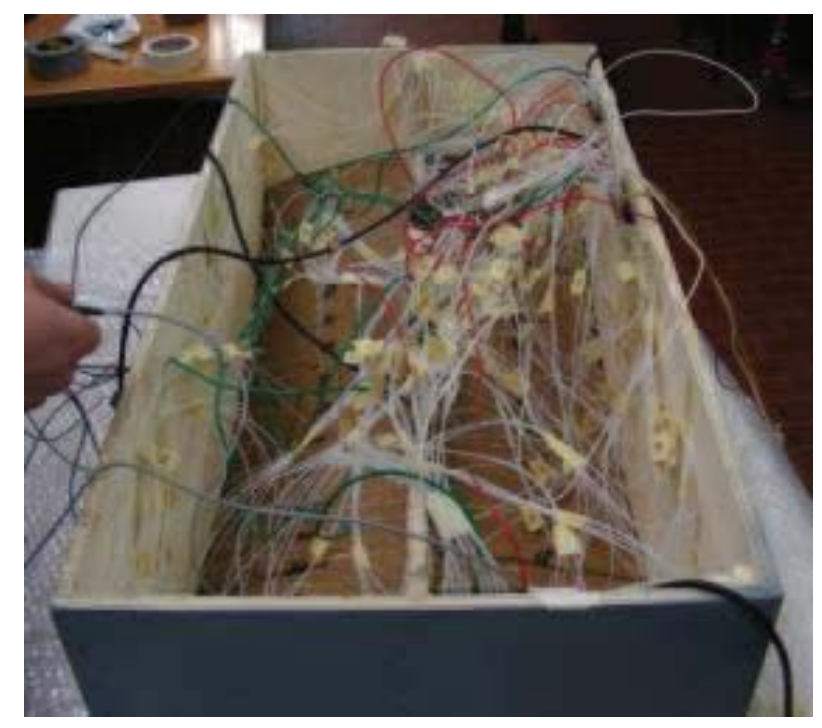

Figure 1: Pressure taps tubes on a large span roof test model.

Pressure taps were located on the model external surfaces and more thickly along edges were the flow detachment occurs. In these zones the pressure coefficient is generally bigger than elsewhere for both values, the mean, and the peak value. In these zones the processes are generally non-Gaussian [19].

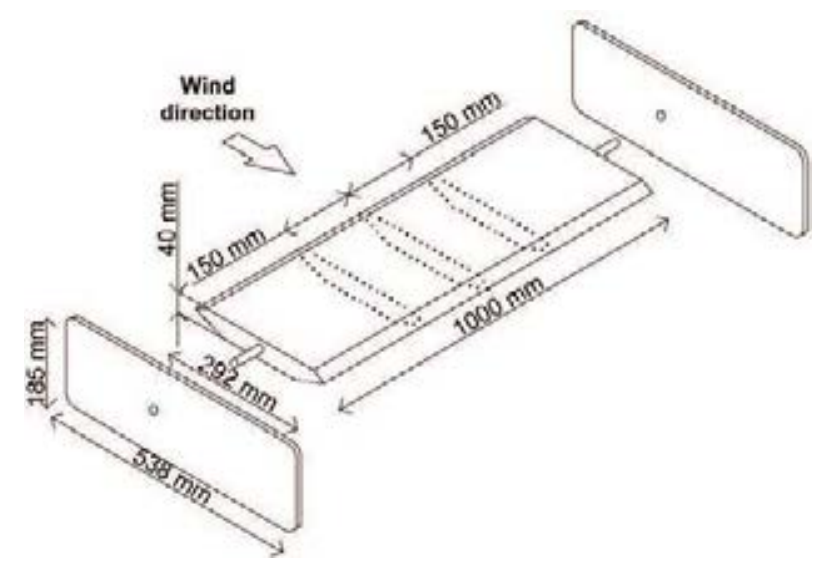

Figure 2: Test model setup for a closed box section model $[6,13]$.

The pressure coefficients time histories were analyses to estimate the Gaussianity observing the empirical cumulative density function (ECDF), the skewness and the excessive kurtosis of the processes.

If the ECDF of the local peaks of the random process is fitted by a Rayleigh distribution, the processes is Gaussian [18]. Otherwise, it the ECDF of the local peaks is fitted by a Weibull distribution it corresponds to a non-Gaussian condition. 
According to [24] the roof regions where the pressure coefficient process is non-Gaussian are identified by the skewness bigger than 0.5 and/or the excessive kurtosis bigger than 0.5 .

\section{GAUSSIAN AND NON-GAUSSIAN PROCESSES}

In this study the assumption given by [24] was assumed to select Gaussian and nonGaussian processes. They were compared with the $95 \%$ level of confidence of the Davenport peak factor [18-19], for two set of data, pressure coefficients time history of hyperbolic paraboloid roofs [20] (Figs. 3-5) and of an example of closed box section for suspended pedestrian bridge [6, 13] (Fig.6). In Figs. 3-6, graphs show the peak factor $g_{\mathrm{p}}$ for each pressure taps \#, gray continues line means the 95\% Davenport level of confidence [18], green squared dot means non-Gaussian processes and finally red dot means Gaussian processes.

Figures 3 show a comparison between a flutter (Fig.3a) and a more curved (Fig.3b) roofs and it was observed that the curvature promotes the non-Gaussian processes decreasing.

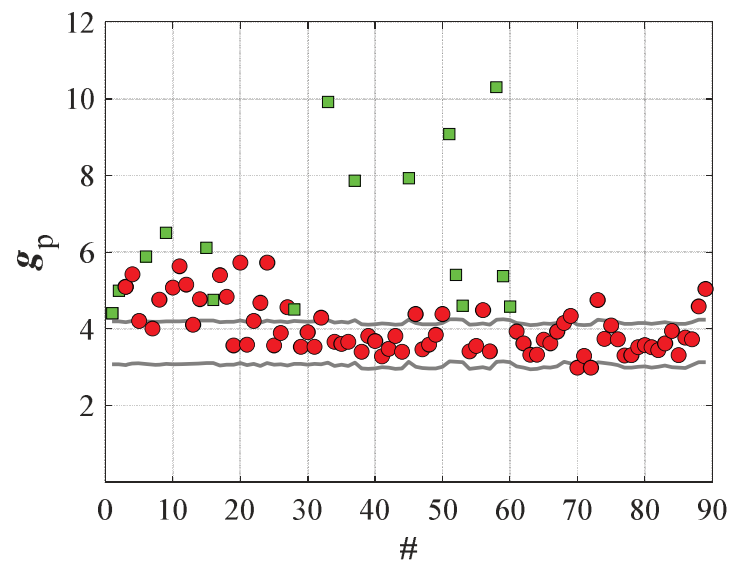

(a)

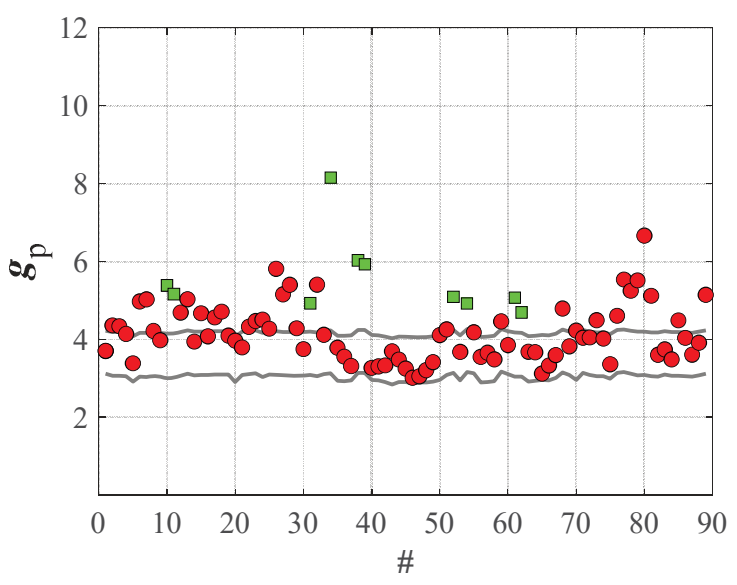

(b)

Figure 3: Gaussian and non-Gaussian processes for hyperbolic paraboloid roof: comparison between flatter (a) and more curved (b) roof.

Figure 4 shows a comparison between low (Fig.4a) and tall (Fig.4b) building covered with a hyperbolic paraboloid roof. It was observed that the building height slightly increase the number of non-Gaussian processes.

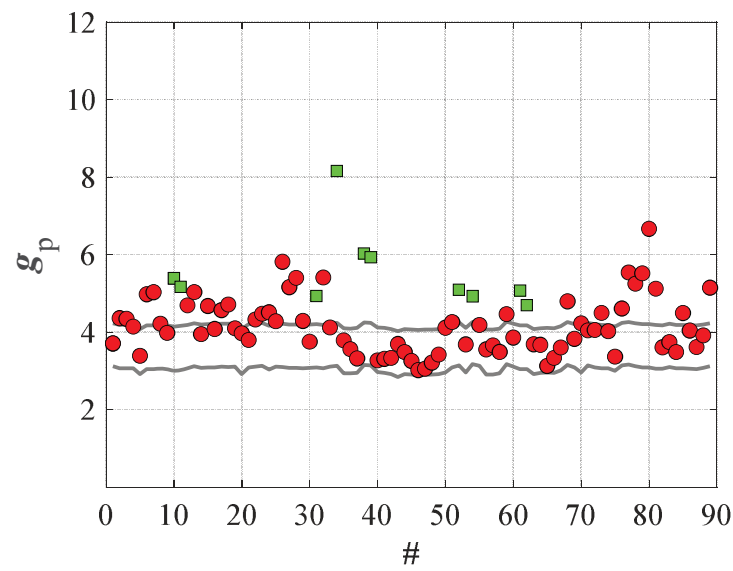

(a)

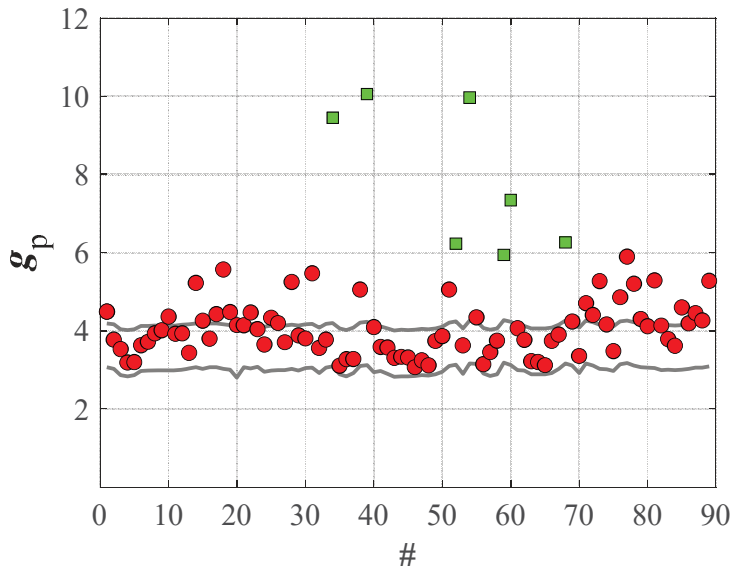

(b)

Figure 4: Gaussian and non-Gaussian processes for hyperbolic paraboloid roof: comparison between low (a) and tall (b) building. 
Figure 5 shows a comparison between two wind angles, $0^{\circ}$ (Fig.5a) and $90^{\circ}$ (Fig.5b). For the wind angle equal to $0^{\circ}$ the flow is parallel to cables with a downward curvature, for the wind angle equal to $90^{\circ}$ the flow is parallel to cables with an upward curvature. It was observed that the wind direction closely affects the Gaussianity. Fig.5b shows that the number of non-Gaussian process for $90^{\circ}$ is bigger than $0^{\circ}$.

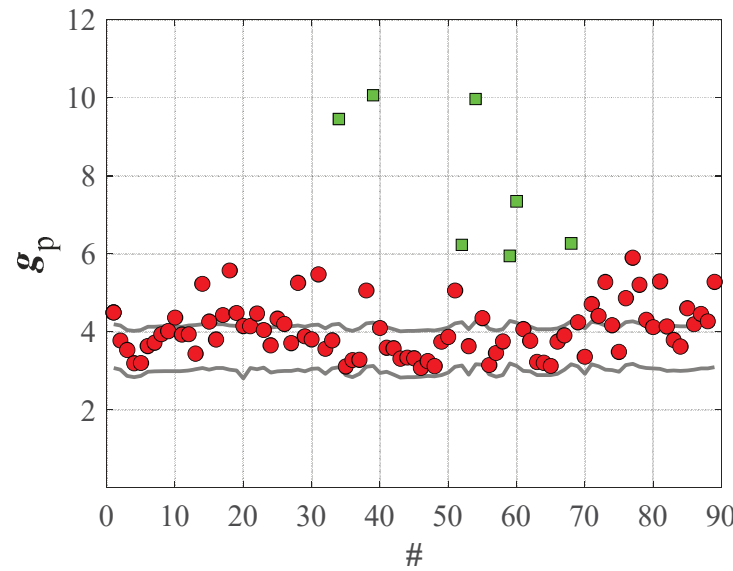

(a)

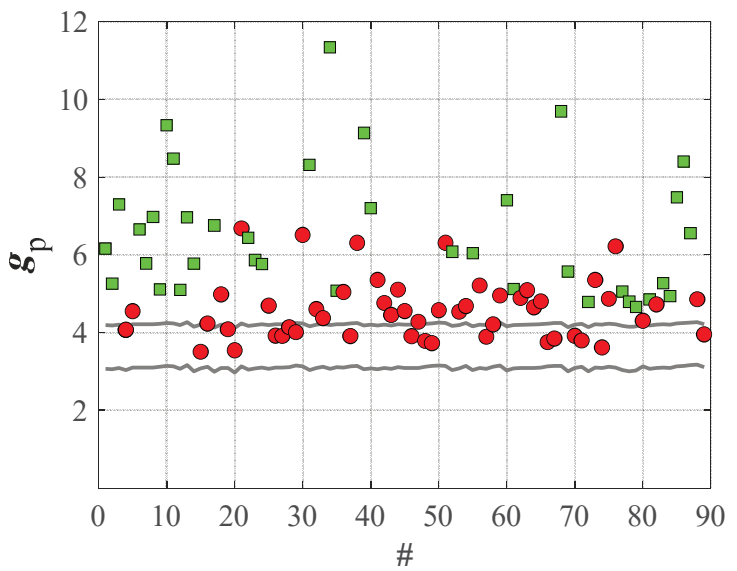

(b)

Figure 5: Gaussian and non-Gaussian processes for hyperbolic paraboloid roof: comparison between wind angle equal to $0^{\circ}$ and $90^{\circ}$.

Figure 6 shows results for a closed box section (Fig.2) with two angles of attach, $-10^{\circ}$ and $0^{\circ}$, respectively. Results show a very relevant difference between the two configurations (Fig.6a and Fig.6b). The number of Gaussian process decreases from $-10^{\circ}$ to $0^{\circ}$ due to the aerodynamics.

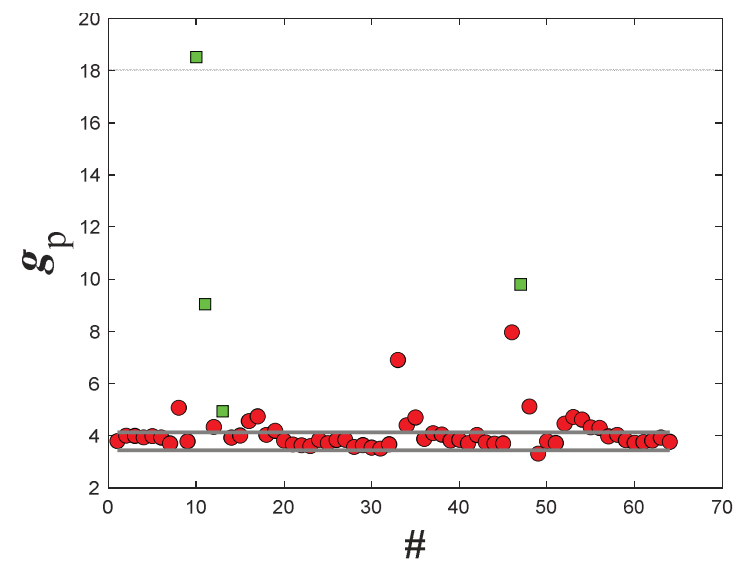

(a)

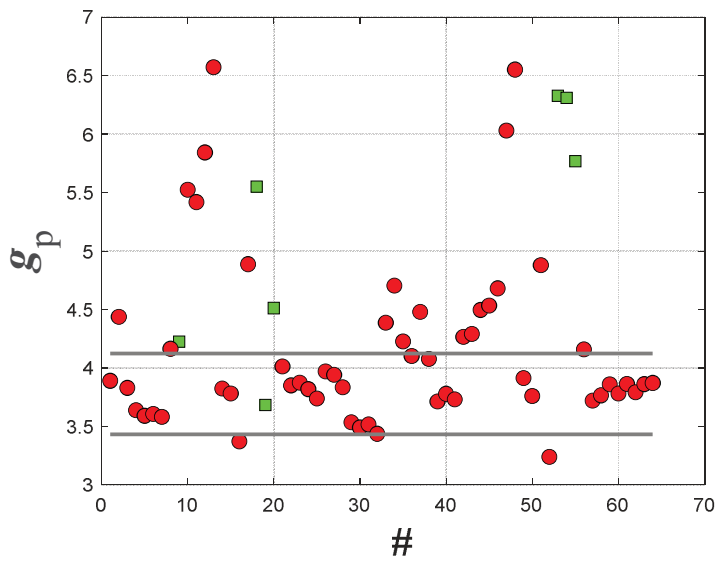

(b)

Figure 6: Gaussian and non-Gaussian processes for closed box bridge section: comparison between angel of attack equal to $-10^{\circ}$ (a) and $0^{\circ}$ (b).

\section{CONCLUSIONS}

The Gaussianity of random processes was investigated on different geometries of roofs and closed box section with different angle of attack. It was observed that:

- For roofs the curvature affects the number of Gaussian processes that increases for flatter roofs. 
- The building height is not relevant in term of number of non-Gaussian processes for the geometry investigated.

- The wind direction closely affect the number of non-Gaussian processes for roofs with a double curvature (i.e. Hyperbolic paraboloid roofs) and during the oscillation of a closed box section for a suspended pedestrian bridge.

Data have shown that non-Gaussian processes are mostly located near edges and near the detachment zones. For these zones the davenport peak factor is not reliable because it underestimates the peaks of the random processes.

\section{REFERENCES}

[1] F. Rizzo, V. Sepe, F. Ricciardelli, A. M. Avossa, Wind pressures on a large span canopy roof". Wind and Structures and International Journal, 30(2): 000-000 DOI: https://doi.org/10.12989/was.2020.30.2.000, 2020.

[2] F. Rizzo, P. Zazzini, Shape dependence of acoustic performances in buildings with a Hyperbolic Paraboloid cable net membrane roof. Journal of Acoustics Australia, 45 (2), 2017.

[3] F. Rizzo, P. Zazzini, Improving the acoustical properties of an elliptical plan space with a cable net membrane roof. Journal of Acoustics Australia, 44, 449-456, 2016.

[4] F. Rizzo, V. Sepe, Static loads to simulate dynamic effects of wind on hyperbolic paraboloid roofs with square plan, Journal of Wind Engineering \& Industrial Aerodynamics, 137, 46-57, 2015.

[5] J. Chilton, Tensile Structures-Textiles for Architecture and Design. In: Pöhl G. ed. Textile Polymers and Composites for Buildings. Woodhead Publishing Limited, Cambridge, England (UK), 229-257, 2010.

[6] F. Rizzo, V. D’Alessandro, S. Montelpare, L. Giammichele, Computational study of a bluff body aerodynamics: impact of the laminar-to-turbulent transition modelling. International Journal of Mechanical Sciences, 178, 15, 105620, 2020.

[7] A. Maria Avossa, D. Di Giacinto, P. Malangone and F. Rizzo, Seismic Retrofit Of A Multi-Span Prestressed Concrete Girder Bridge With Friction Pendulum Devices. Shock and Vibration, 2018, Article ID 5679480, 2018.

[8] F. Rizzo, G. Di Lorenzo, A. Formisano, R. Landolfo, A time-dependent corrosion wastage model for Wrought iron Structures. ASCE's Journal of Materials in Civil Engineering, 31(8): 04019165, 2018.

[9] F. Rizzo, F. Ricciardelli, G. Maddaloni, Bonati A., A. Occhiuzzi, Experimental error analysis of dynamic properties for a reduced-scale high-rise building model and implications on full-scale behavior. Journal of Building Engineering, 28, 2020.

[10] F. Rizzo, A. G. Kopp, G. Giaccu, Investigation of wind-induced dynamics of a cable net roof with aeroelastic wind tunnel tests. Engineering Structures, 229, 111569, 2021.

[11] I. Vassilopoulou, C.J. Gantes, Nonlinear dynamic behavior of saddle form cable nets under uniform harmonic load. Engineering Structures, 33(10), 2762-2771, 2011.

[12] I. Vassilopoulou, C.J. Gantes, Vibration modes and natural frequencies of saddle form cable nets. Computers and Structures, 88(1-2), 105-119, 2012. 
[13] F. Rizzo, L. Caracoglia, Artificial Neural Network model to predict the flutter velocity of suspension bridges. Computers and Structures, 233 (2020) 1062362020.

[14] Letchford C.W., Denoon R.O., Johnson G., Mallam A., 2002. Dynamic characteristics of cantilever grandstand roofs. Engineering Structures, 24(8), 1085-1090.

[15] Going with the flow, Aerospace Engineering \& Manufacturing, March 2009, 27-28 Society of Automotive Engineers.

[16] National Research Council of Italy (CNR), 2018. Guide for the Assessment of Wind Actions and Effects on Structures. CNR-DT 207/2018, Rome (Italy).

[17] European Committee for Standardization (CEN), 2005. Eurocode 1: Actions on Structures - Part 1-4: General Actions - Wind Actions. EN-1991-1-4, Brussels (Belgium).

[18] Davenport A.G., 1964. Note on the distribution of the largest value of a random function with application to gust loading. Institution of Civil Engineering, 28(2), 187-196.

[19] F. Rizzo, M. Barbato, V. Sepe, Peak factor statistics of wind effects for hyperbolic paraboloid roofs. Engineering Structures, 173, 313-330, 2018.

[20] F. Rizzo, C. Demartino, Pressure modes for hyperbolic paraboloid roofs. Curved and Layer Structure, 7, 1-21, 2021.

[21] F. Rizzo, Wind tunnel random processes statistics of pressures on a large span canopy roof. Iranian Journal of Science and Technology, Transactions of Civil Engineering, 10.1007/s40996-020-00458-x, 2020.

[22] J. Colliers, J. Degroote, M. Mollaert, L. De Laet, Mean pressure coefficient distributions over hyperbolic paraboloid roof and canopy structures with different shape parameters in a uniform flow with very small turbulence. Engineering Structures, 205, 110043, 2020

[23] J. Colliers, M. Mollaert, J. Vierendeels, L. De Laet, Collating wind data for doublycurved shapes of tensioned surface structures (Round Robin Exercise 3). Procedia Engineering, 155, 152-162, 2016.

[24] K. Suresh Kumar, T. Stathopoulos, Wind loads on low building roofs: a stochastic perspective. Journal of Structural Engineering, 126(8), 944-956, 2000.

[25] K.R. Gurley, M.A. Tognarelli, A. Kareem, Analysis and simulation tools for wind engineering. Probabilistic Engineering Mechanics, 12(1), 9-31, 1997.

[26] M.F. Huang, W. Lou, C.M. Chan, N. Lin, X. Pan, Peak distributions and peak factors of wind-induced pressure processes on tall buildings. Journal of Engineering Mechanics, 139(12), 1744-1756, 2013.

[27] C.G. Huntington. The Tensioned Fabric Roof. American Society of Civil Engineers (ASCE), Reston, VA (USA), 2004.

[28] C.G. Huntington, Tensile Fabric Structures. Design, Analysis, and Construction. American Society of Civil Engineers (ASCE), Reston, VA (USA), 2013.

[29] A. Kareem, J. Zhao, Analysis of non-Gaussian surge response of tension leg platforms under wind loads. Journal of offshore Mechanics and Arctic Engineering, 116(3), 137144, 1994. 
[30] D. Kwon, A. Kareem, Peak factors for non-Gaussian load effects revisited. Journal of Structural Engineering, 137(12), 1611-1619, 2011.

[31] M. Liu, X. Chen, Q. Yang, Characteristics of dynamic pressures on a saddle type roof in various boundary layer flows. Journal of Wind Engineering and Industrial Aerodynamics, 150, 1-14, 2016.

[32] M. Liu, X. Chen, Q. Yang, Estimation of peak factor of non-Gaussian wind pressures by improved moment-based Hermite model. Journal of Engineering Mechanics, 143(7):06017006, 2017. 